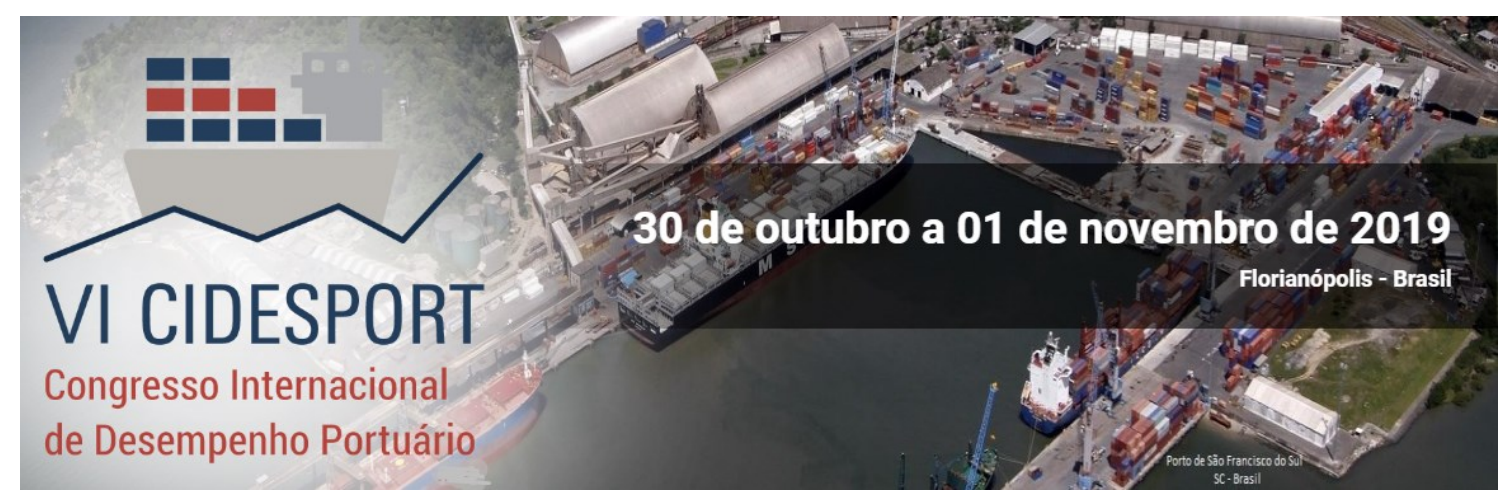

\title{
PROPOSTA DE APERFEIÇOAMENTO DO PROCESSO DE FISCALIZAÇÃO TRIBUTÁRIA DE ISS NO SETOR PORTUÁRIO DO MUNICÍPIO DE PARANAGUÁ - PR
}

\author{
Amanda Maciel Carneiro \\ Universidade do Estado de Santa Catarina \\ Fabiano Maury Raupp \\ Universidade do Estado de Santa Catarina \\ Leonardo Secchi \\ Universidade do Estado de Santa Catarina
}

\begin{abstract}
Resumo: Essa pesquisa foi realizada com o objetivo de propor alternativas para o aperfeiçoamento do processo de fiscalização tributária de ISS no setor portuário do município de Paranaguá - PR. Apresentou metodologia de característica qualitativa, em pesquisa exploratório-descritiva, enfoque analítico e prescritivo, e método de estudo de caso. A coleta de dados se deu em entrevistas semi-estruturadas com 12 auditores fiscais do Município e apoio de documentos e dados secundários, com posterior análise de conteúdo, análise documental e técnica de triangulação. Os resultados evidenciaram processos de fiscalização, dificuldades encontradas e sugestões de melhoria dos próprios entrevistados que, somados ao referencial teórico, permitiram a elaboração de um conjunto de ações de atuação interna, investimentos e atuação externa com vistas a aperfeiçoar os processos em questão. As conclusões apontaram fomento à escassa literatura, resultados positivos de atuação do corpo técnico, apesar da existência de níveis de conhecimento entre os entrevistados e das dificuldades encontradas, atuações distintas no início do processo, resultados e técnicas de fiscalização e experiências, teses, existência de referências internas, uso de triangulação e informações de terceiros, ambiente portuário dinâmico e complexo, necessidades de capacitação e atualização constantes e possibilidade de uso mais estratégico dos sistemas informatizados. Sobretudo, evidenciaram-se espaços para o aperfeiçoamento dos processos; coerência entre a metodologia, os achados e as intervenções propostas; atingimento dos objetivos pela descrição do processo pelo diagnóstico das dificuldades nele encontradas e pela identificação de alternativas administrativas e legais de aperfeiçoamento dele; e contribuições à comunidade acadêmica, à Prefeitura de Paranaguá, ao corpo técnico e à sociedade. Pode-se afirmar que o aperfeiçoamento desejado tanto é possível quanto viável, e que, caso ocorra, apresenta grande potencial transformador e coaduna com a perseguição de excelência no serviço público, na constante busca pela satisfação dos anseios coletivos.
\end{abstract}

Palavras-chave: Fiscalização tributária. ISS. Setor portuário.

\section{INTRODUÇÃO}

* A revisão gramatical, ortográfica, ABNT ou APA foi realizada pelos autores. 
A fim de alcançar o fim máximo estatal, quer seja ele, a satisfação dos anseios coletivos, necessário se faz que haja receita suficiente para atender a essas demandas (SANTOS, 2006; MARTINS, 2009; NABAIS, 2012). A tributação surge, nesse cenário, como forma de tornar o cidadão contribuinte dessa receita, auxiliando monetariamente os entes a fim de que promovam as transformações sociais desejadas (MACHADO, 2009; AMARO, 2013; CARRAZA, 2015; FOLLONI; DIB, 2015). Dentro dos contornos legais do poder de tributar, coube à fiscalização e arrecadação tributária, funções da Administração Tributária, conforme o Código Tributário Nacional (CTN) (BRASIL, 1966), atuar de forma ativa tanto na administração quanto na efetiva coleta da receita tributária, sendo partícipe da política fiscal e provendo análises de consultas, pareceres e informações relacionadas (MARIA; LUCHIEZI JÚNIOR, 2010). A fiscalização, alvo desse estudo, é atividade derivada da auditoria fiscal da Fazenda dos entes, atividade estratégica para propiciar a arrecadação e recolhimento dos tributos dentro das esferas de competência (CAMPANHA, 2010).

A divisão federativa brasileira impôs distribuição de receita entre os entes, a fim de fazer frente aos encargos administrativos a ele vinculados (conforme artigo $145 \mathrm{e}$ seguintes da Constituição Federal vigente) (BRASIL, 1988). Cabe a esse estudo especial atenção aos Municípios, que obtiveram, como receitas próprias e privativas de impostos, a competência de três deles, importando a esse estudo o Imposto Sobre Serviços de Qualquer Natureza, não compreendidos os de competência estadual, definidos em lei complementar (ISS). No contexto atual, o ISS apresenta posição de destaque, sendo considerada a maior fonte de arrecadação tributária própria municipal, consoante estudo do Ministério da Fazenda (2018).

Diante disso, apresenta-se o município de Paranaguá, situado ao leste do Paraná como objeto empírico desse estudo; município este que apresenta, dentre outras, a característica de contemplar o principal porto de graneis sólidos da América Latina, com recordes sucessivos de exportação de soja e farelo de soja (APPA, 2018a). A movimentação de atividades do Porto de Paranaguá afeta financeira e economicamente a economia estadual e nacional, e impacta diretamente a economia e a sociedade local (GODOY, 2000; MATTOZO, 2006; SOARES, 2009), com reflexos significativos no processo fiscalizatório e arrecadatório de ISS do setor portuário no município (AEN, 2017; IPM SISTEMAS, 2017b). Por todo o exposto, aí se apresenta a delimitação deste estudo: o processo de fiscalização tributária de ISS no município de Paranaguá referente aos setores portuários, correspondentes ao subitem 20.01 da Lei Complementar Federal 116, de 31 de julho de 2003 (LC 116/2003) - a lei instituidora de normas gerais do imposto - que segue:

20.01 - Serviços portuários, ferroportuários, utilização de porto, movimentação de passageiros, reboque de embarcações, rebocador escoteiro, atracação, desatracação, serviços de praticagem, capatazia, armazenagem de qualquer natureza, serviços acessórios, movimentação de mercadorias, serviços de apoio marítimo, de movimentação ao largo, serviços de armadores, estiva, conferência, logística e congêneres. (BRASIL, 2003).

No caso do município de Paranaguá, esse subitem, 20.01, aparece como itens 20.01 e 20.05 da lista de serviços anexa à Lei Complementar Municipal 110, de 18 de dezembro de 2009 (lei municipal instituidora do imposto) (LC 110/2009), separando o subitem de armazenagem relativa aos serviços portuários em item 20.05 , relacionado também ao item geral 20, "Serviços portuários, aeroportuários, ferroportuários, de terminais rodoviários, ferroviários e metroviários” (PARANAGUÁ, 2009). 
Relacionam-se, assim, o ISS como grande importância de receita própria municipal, o impacto da movimentação portuária no ente local e o processo de fiscalização tributária intrinsecamente relacionado a essa atividade. A isso, associamse princípios de justiça fiscal e de leal concorrência (CAMPANHA, 2010; GODOY; BASSO, 2015; MARIA; LUCHIEZI JÚNIOR, 2010), assim como de eficiência administrativa (MADEIRA, 2010). Ainda, reconhece-se o incremento substancial de receita arrecadada pelo Município nos últimos anos, com paulatino progresso nos resultados entregues pela atividade fiscalizatória (PARANAGUÁ, 2017c; 2018b). A melhoria contínua de ações de fiscalização, nesse sentido, e o potencial incremento de arrecadação consubstancia-se, assim, na busca de fomentar condições de materialização de direitos sociais e de vivência digna à população, dever maior estatal.

Esse contexto abre a oportunidade de voltar as atenções ao problema de pesquisa que aqui se apresenta: a possibilidade de aperfeiçoamento do processo de fiscalização tributária do ISS sobre os serviços relacionados à atividade portuária no município de Paranaguá - PR. A escolha de aperfeiçoamento dos processos relacionados aos serviços específicos operações portuárias se deu pela importância (econômica, financeira, social) que o Porto de Paranaguá tem na região e no País, pela quantidade de movimentação de serviços e valores envolvida, impactando na arrecadação municipal de receitas próprias de impostos, e pela representatividade que o ISS tem como fonte de receita própria do município. Somada à escassez de literatura neste sentido, o estudo se desenhou com o objetivo de propor alternativas para o aperfeiçoamento do processo de fiscalização tributária de ISS no setor portuário do município de Paranaguá - PR.

\section{REFERENCIAL TEÓRICO}

O tributo tem amparo legal e constitucional na estrutura brasileira, e seu conceito é descrito no artigo $3^{\circ}$ do CTN da seguinte forma: "Tributo é toda prestação pecuniária compulsória, em moeda ou cujo valor nela se possa exprimir, que não constitua sanção de ato ilícito, instituída em lei e cobrada mediante atividade administrativa plenamente vinculada" (BRASIL, 1966). É, assim, o tributo: prestação pecuniária compulsória, que nasce independente da vontade do contribuinte; não se confunde com atos ilícitos, ou seja, não é penalidade; tem sua criação vinculada à lei e, em se tratando de carreamento de valores públicos para o público, não permite espaço para apreciação de conveniência ou oportunidade de agir, sendo obrigatoriamente vinculado à lei (MACHADO, 2009).

A tributação, nesse sentido, se incumbe de área meio, política pública para o financiamento estatal e instrumento fundamental de ação governamental (ALEXANDRE, 2015; SECCHI, 2013). É considerada "o preço da cidadania" (MARIA; LUCHIEZI JÚNIOR, 2010, p. 14) e instrumento de dignidade de justiça social (FOLLONI; DIB, 2015), embora estudos variados analisando o comportamento do contribuinte e a sonegação fiscal identifiquem análises de risco e retorno baseadas em fatores variados realizadas pelos contribuintes e definidoras de sua atuação frente ao dever de cumprimento tributário, o correto pagamento de tributos devidos (como em ALLINGHAM; SANDMO, 1972; CHANG; NICHOLS; SCHULTZ, 1987; BERTOLUCCI; NASCIMENTO, 2002; SIQUEIRA RAMOS, 2005; GRYZBOVSKI; HAHN, 2006; PANTOJA; PEÑALOZA, 2014; VIOL, 2015; PEREIRA, 2017). A sonegação pode ser considerada, para Campanha (2010), como postura anticoncorrencial com condutas desonestas, e para Turolla (2009) e Leite (2011) e Godoy e Basso (2015), uma conduta antissocial. Para ver propostas de combate à 
VI CIDESPORT/2019

Congresso Internacional

de Desempenho Portuário

sonegação, sugerem-se os estudos de Schmitz (2010), Leite (2011) e Miranda (2013), dentre outros.

No Brasil, a tributação foi estruturada dentro da federação, que consta de União, Estados e Municípios - a todos são atribuídos encargos, e a todos, receitas para custearem esses encargos (BRASIL, 1988). Alvo dessa pesquisa, restaram aos Municípios, além dos tributos comuns (taxas e contribuições de melhoria), a receita própria de três impostos. Sendo imposto "tributo cuja obrigação tem por fato gerador uma situação independente de qualquer atividade estatal específica, relativa ao contribuinte.", consoante artigo 16 do CTN (BRASIL, 1966), dentre os municipais, enfocamos o ISS (BRASIL, 1988).

Acerca do ISS, pode-se falar em antecedentes históricos na tributação das atividades de tinturaria, ourives e curtidor, dentre outras, no Egito, Roma e Grécia (PAIVA, 2005). Nas últimas décadas, a reforma tributária francesa de 1954 instituiu a taxe sur la valeur ajountée (TVA) e a taxe sur les prestations de services (TPS), sendo a primeira tributadora do valor acrescido e a segunda sobre o preço total, similar ao que ocorre hoje com o ICMS e o ISS, respectivamente (KORFF, 1977). Tem o ISS seu nascimento no Brasil na Emenda Constitucional n. 18, de 1 de dezembro de 1965, porém suas raízes remontam aos antigos impostos em determinadas atividades lucrativas e profissões, datados de 1812, e transações e diversões públicas (PAIVA, 2005).

Os contornos legais do ISS são trazidos pela LC 116/2003, e também pela legislação de cada ente municipal. Seu fato gerador (ocorrência no mundo material que se enquadra no disposto legalmente) (AMARO, 2013) é prestar serviços dentro das disposições da lei, respeitando seus ditames e guiando-se pela lista que segue anexa à lei federal para compreensão das atividades relacionadas. Essa lista anexa consta hoje de 40 itens e vários subitens, que somam cerca de 200 hipóteses definidas em itens com descrições e previsão de serviços congêneres.

Ainda sobre os elementos do ISS, sua base de cálculo é o preço do serviço (art. $7^{\circ}$ da LC 116/2003), e suas alíquotas podem orbitar entre dois a cinco por cento (arts. $8^{\circ}$ e 8-A da mesma lei). Participam da relação, como sujeito ativo, pessoa jurídica de Direito Público titular da competência para exigir o seu cumprimento, o Município e de outro lado, o contribuinte que efetivamente presta o serviço ou seu responsável legal (LC 116/2003). O momento é o da ocorrência do fato gerador, e o local, geralmente, o do estabelecimento do prestador, salvo hipóteses elencadas na LC 116/2003 (BRASIL, 2003).

Peça estratégica, assim, no recolhimento de valores, é a atividade de fiscalização tributária, que integra a auditoria fiscal, esta que tem como finalidade o correto cumprimento das exigências da lei tributária (ARAÚJO NETO; SILVA, 2010; CAMPANHA, 2010; LAGIOIA et al., 2011; OLIVEIRA, 2012). Abrange a auditoria fiscal a fiscalização, que é mais pontual e específica, e objetiva a conferência da efetividade do cumprimento das obrigações por atos simples, como a atuação em plantões fiscais e solução de dúvidas, bem como por atos complexos, que demandam maior esforço de notificação, conferência de documentos e atos necessários à conferência da correta aplicação dos ditames tributários, muitas vezes fora das repartições públicas (FRANÇA, 2012). Esses processos, preventivos ou repressivos, cabem as pessoas legalmente designadas, servidores públicos geralmente ocupantes do cargo de auditor fiscal (MARIA; LUCHIEZI JÚNIOR, 2010). Tem a administração fazendária e seus servidores fiscais precedência sobre as demais atividades administrativas por disposição constitucional (art. 37, XVIII) (BRASIL, 1988). 
Geralmente, a figura associada à competência de fiscalização tributária é a de auditor fiscal, cujo cargo e função exigem grandes responsabilidades e são de grande complexidade (MARIA; LUCHIEZI JÚNIOR, 2010). A atuação da Administração Tributária vem disciplinada nos artigos 194 a 200 do CTN (BRASIL, 1966), cujo poder de examinar livros comerciais, quanto aos pontos de investigação em análise, já foi pacificado em Súmula do Supremo Tribunal Federal (STF, 1964) e aparece também no Código Civil brasileiro em seu artigo 1193 (BRASIL, 2002). Os modos de conferir os fatos e os meios utilizados "permitem um juízo de conveniência e oportunidade às autoridades fiscais" (PUGLIESI, 2010, p. 136), no que se percebe que a reunião dessas informações e a forma de analisá-las compete à atuação da auditoria fiscal. Determinar o que são evidências suficientes e apropriadas cabe a cada profissional, dentro do seu julgamento, experiência e ceticismo profissional, conceito emprestado da Auditoria Independente (CFC, 2016). Ainda assim, documentos fiscais, notas, livros e autorizações (TCU, 2003), bem como escrituração e documentação digital (FRANÇA, 2012), dentre outros, são geralmente fontes de informação.

No que se refere à cobrança do ISS, estudos mencionam escassez de auditores qualificados, cadastros pouco representativos, legislação inadequada, falta de integração e de comunicação com outros entes, poucas ferramentas de informática para suporte e prática comum de anistias fiscais gerando a expectativa de não pagamento pelo contribuinte como dificuldades comuns na fiscalização e cobrança, citadas pela literatura há tempos (AFONSO et al., 1998) e, apesar disso, muitas ainda atuais (CAMPANHA, 2010; CURY; 2013; MARTINS, 2016). A fiscalização do ISS relativo à importação de serviços e na exportação de serviços desenvolvidos no Brasil cujo resultado aqui se verifique (art. $1^{\circ}, \S^{\circ}$, e art. $2^{\circ}$, I, parágrafo único, LC 116/2003) é campo nebuloso, pela falta de competência na fiscalização do tomador do serviço, sem saber como e se o serviço de fato aconteceu ou se houve o correspondente pagamento, abrindo espaço para conluio entre as partes (ZILVETI; COELHO, 2009).

A falta de recursos materiais como veículos para vistoria também é enumerada como ponto deficitário na fiscalização do ISS (FERREIRA; KANAANE; SEVERINO, 2010), e a emissão das notas fiscais, quando manuais, abre espaço para adulteração nas vias e para erros de escrituração (SCHMITZ, 2010). A falta de capacitação em áreas-chave como direito tributário e contabilidade e parcos investimentos em recursos e planejamento desvalorizam a fiscalização municipal, impactando na imagem de pouca credibilidade normalmente associada aos fiscos locais (CAMPANHA, 2010). Tangenciando o assunto, Soares Neto e Silva (2012), em estudo sobre os estágios de aprendizagem dos auditores fiscais, falam sobre o impacto do curso de formação de auditores, observação da prática, acompanhamento do auditor novato por um veterano, reflexão no início da prática, partilha de experiências e desenvolvimento de capacidade para posteriormente ensinar como elementos da criação interna de conhecimento na função. As restrições de período decadencial e a elevada gama de contribuintes a serem fiscalizados, quando associadas a escassos recursos humanos e materiais, apresentam-se como fatores que dificultam o alcance do resultado desejado (LAGIOIA et al., 2011). O aperfeiçoamento e realização de investimentos em auditoria e fiscalização, assim, são vistos como de suma importância para a administração e para os administrados (CAMPANHA, 2010).

Quanto aos estudos acessados, percebem-se relações entre alguns (como os de Gil (2002) e Paiva (2005)) ao tratarem de propostas e análises de implementações de Programas de Modernização voltados à área de fiscalização, e entre outros, ao analisarem cenários e dificuldades encontrados em processos de fiscalização tributária (como em Campanha (2010), Cury (2013) e Martins (2016)), no que se 
assemelham ao estudo pretendido ao buscar aprofundamento em questões de fiscalização de ISS, e se distanciam no sentido de que nenhum abordou a fiscalização do ISS sob a ótica dos serviços relacionados às operações portuárias. Percebem-se também relações mais distantes com estudos que analisam a fiscalização sob a ótica da gestão e governança (como em Ribeiro (2011) e Yoshiura (2016)), embora interessantes como referenciais e importantes como parâmetro do desenvolvimento do instrumento de coleta.

Evidenciou-se a ausência de estudos específicos de fiscalização tributária em operações portuárias, mesmo quando abordados municípios com Portos, como Manaus (GIL, 2002) e Vitória (PAIVA, 2005). A escassez de estudos de fiscalização tributária, mesmo em sentido macro, já foi apontada inclusive Afonso et al. (1998) e por França (2012), situação à qual este se refere como "lacuna doutrinária" (2012, p. 89). Daí a necessidade de esclarecer o contexto em que se realizam as operações portuárias, com ênfase no cenário brasileiro, e suas particularidades, para a compreensão de como se dá a fiscalização de ISS nessas atividades.

O transporte marítimo faz parte de fenômeno de grande complexidade e traz a estrutura portuária como elo entre modais (MACHADO, 2016). A expansão de sua atividade se relaciona à modernização (MONIÉ; VIDAL, 2006), com o aumento dos fluxos de comércio exterior e a consequente "redução do tempo gasto com a circulação das cargas no espaço, possibilitando a conquista de mercados distantes geograficamente (importações e exportações)" (FELIPE JUNIOR, 2015, p. 68). Diversas são as cargas transportadas e os tipos de embarcações existentes atualmente (FELIPE JUNIOR, 2015) que se relacionam com a atividade portuária, atividade esta complexa, "que abrange inúmeros serviços desde a chegada e entrada do navio no porto, seu atracamento, transbordo de cargas e saída para um novo destino, com reflexos diretos e indiretos na economia dos municípios" (SOARES, 2009, p. 2).

A referência principal das atividades portuárias se baseou em Soares (2009), que apresentou um esquema didático das atividades, trazendo as figuras de agenciador marítimo (representante do armador, dono do navio) e operador portuário (responsável pela operação de carregamento e descarregamento das mercadorias quando o navio está no cais), bem como a existência de documentos como o manifesto de carga e a fatura comercial e de equipamentos para movimentação das cargas (SOARES, 2009). As atividades de fundeamento em alto-mar, verificações e inspeções, praticagem, reboque, atracação, ancoração e amarração, operação portuária propriamente dita com o navio no cais (mencionadas tipicamente como capatazia, estiva, conferência de carga, conserto de carta, vigilância de embarcação e bloco pela Nova Lei dos Portos), armazenagem e transporte, assim como acessórias de conserto, higienização, reparo de acidentes e ampliação do tempo de armazenagem, ensacamento de carga e estufamento de contêiner, unitização de carga (acondicionamento em lote-padrão em estruturas como pallets e contêineres para facilitar a movimentação), fumigação, etc. são atividades associadas à portuária (SOARES, 2009; APPA, 2016).

Foco dessa pesquisa, o município de Paranaguá, no Paraná, de população estimada em 2018 de mais de 150 mil pessoas (IBGE, 2018), comporta o Porto de Paranaguá desde 1935, cuja história data de um atracadouro de 1872 (PARANAGUÁ, 2018a), considerado hoje o "maior porto graneleiro da América Latina" (APPA, 2018a). É administrado pela APPA, autoridade portuária na condição da empresa pública em concessão do governo federal ao estadual, a qual tem, dentre outras, a 
VI CIDESPORT/2019

Congresso Internacional

de Desempenho Portuário

responsabilidade de qualificar os operadores portuários e manter relatórios de todas as movimentações realizadas (APPA, 2018a).

O escoamento de cargas pelo Porto de Paranaguá atinge uma corrente de comércio abrangendo mais de 200 portos mundiais no sentido da exportação, e mais de 150 no sentido da importação, tendo como principais destinos de exportação China, Holanda, Argentina, Alemanha e Coreia do Sul, e de importação China, Argentina, Alemanha, EUA e França (APPA, 2018b). Grande parte de sua movimentação se dá por conta dos graneis agrícolas, que bate recordes sucessivos de soja e farelo de soja, na exportação, e de fertilizantes na importação (ANTAQ, 2018). O Portal Compara Brasil e dados internos da Prefeitura de Paranaguá deixam claro o quanto a arrecadação de ISS é a principal fonte de receitas municipal (COMPARA BRASIL, 2018; IPM SISTEMAS, 2017a). O sistema informatizado da Prefeitura evidencia que 9 entre 10 dos maiores arrecadadores de ISS do município são diretamente relacionados ao Porto, e o outro, indiretamente relacionado (IPM SISTEMAS, 2017b).

Considerando as descrições de Soares (2009) e da APPA (2016), percebemse, assim, diversos serviços relacionados à atividade portuária passíveis de enquadramento no ISS, por constituírem-se fatos geradores do imposto em questão: podem-se realizar cessão de estruturas de uso temporário, constantes no subitem 3.05; Possíveis reparações e conservações de portos são previstas no subitem 7.05; serviços de dedetização e congêneres encontram-se no subitem 7.13, e de limpeza e dragagem, no subitem 7.18, todos partes do item 7 , que contempla "serviços relativos a engenharia, arquitetura, geologia, urbanismo, construção civil, manutenção, limpeza, meio ambiente, saneamento e congêneres" (BRASIL, 2003); o agenciamento marítimo é previsto no subitem 10.06; serviços de guarda, estacionamento, armazenamento, vigilância e congêneres (fora da área do porto organizado, nas operações no retroporto), são previstos no item 11. Serviços de prestações a terceiros, como assistência, manutenção, limpeza, içamento e guincho, entre outros, se encontram no item 14; o transporte intramunicipal está disposto no item 16; serviços de apoio técnico, administrativo, jurídico, contábil, comercial e congêneres, previstos no item 17; e serviços de desembaraço aduaneiro, comissários, despachantes e congêneres, no item 33. Além, é claro, dos serviços portuários propriamente ditos (referentes ao subitem 20.01 da LC 116/2003, replicado em subitens 20.01 e 20.05 da LC 110/2009), que são devidos ao local do porto (BRASIL, 2003).

Para acompanhar toda essa movimentação e realizar a fiscalização propriamente dita, sugere Cury (2013) o uso de documentos e livros de escrituração de prestadores e tomadores de serviço, contratos, históricos de atuação e informações estratégicas de sistemas informatizados. Os documentos de transporte podem também ser de grande valia para a fiscalização dessas atividades (SEIXAS, 2014), assim como relações de dados dos navios e das cargas das autoridades portuárias (APPA, 2016). Acompanhamentos in loco, como o realizado pela Prefeitura de Santos com a capacitação de auditores fiscais para realizarem buscas em toda a cadeia produtiva da movimentação portuária, cujo resultado nos seus primeiros meses foi a emissão de mais de 40 notificações e o incremento de arrecadação de cerca de $\mathrm{R} \$ 8$ milhões, associam-se em resultados positivos com sistemas de cruzamentos de dados (SINDOGEESP, 2013). Informações de outros entes estatais (como fazendas estaduais e federais, autoridades marítimas e de defesa nacional, dispostos ao longo da Constituição) são auxiliares e coadunam com a atuação integrada prevista no corpo constitucional, art. 37, XXII (BRASIL, 1988). 
VI CIDESPORT/2019

Congresso Internacional

de Desempenho Portuário

\section{PROCEDIMENTOS METODOLÓGICOS}

Quanto aos objetivos, apresentou característica exploratória-descritiva, com enfoque analítico e prescritivo. Exploratória haja vista a familiarização do assunto, explicitando e aprofundando o problema; descritiva ao descrever os fenômenos, identificando-os, relatando-os e comparando-os (RAUPP; BEUREN, 2003). A análise dos dados coletados e a elaboração da proposta visando recomendação de intervenção social evidenciam os outros dois aspectos (SECCHI, 2016). O método de pesquisa utilizado foi o estudo de caso, pela natureza e assunto investigados (YIN, 2005). O objeto empírico compreendeu o processo de fiscalização tributária de ISS no setor portuário do município de Paranaguá - PR. A pesquisa pode-se caracterizar, ainda, como documental, utilizando-se de registros de fatos e fenômenos para sustentação (RAUEN, 2005), e de abordagem qualitativa, permitindo conhecer a natureza do fenômeno através das variáveis levantadas e suas interações, inclusive com a percepção do pesquisador (RAUPP; BEUREN, 2003).

Dentre os instrumentos de coleta, utilizaram-se entrevistas de profundidade e semi-estruturadas com 12 dentre os 19 Auditores Fiscais da Fazenda Municipal de Paranaguá, realizadas entre 25/01/2019 e 22/02/2019, com cerca de 40 minutos cada, e com base em Triviños (1987), Alves (2003) e Yin (2005). Inicialmente elaborado com base em Gil (2002), Cury (2013), Martins (2016) e Yoshiura (2016), adaptados para alcançar os objetivos desta pesquisa, com suporte em modelo de Visão Baseada em Recursos de Wernerfelt e Barney, elaborado por Carvalho, Prévot e Machado (2013), o roteiro foi readaptado após um primeiro pré-teste em 07/12/2018 e confirmado após um segundo pré-teste em 14/12/2018, realizados com dois auditores distintos componentes do quadro. Todos esses contatos se deram ao vivo e individualmente.

Buscou-se responder questões relacionadas às categorias processo de fiscalização e recursos e técnicas, referentes à dimensão processos; categorias de experiências própria e de terceiros, referentes à dimensão experiências; categoria dificuldades encontradas; referente à dimensão gargalos; e categorias sugestão de melhorias de processo e sugestões de minimização de gargalos, referentes à dimensão sugestões.

Aliados a esse, foi realizado levantamento de documentos relacionados à atividade, consultaram-se fontes secundárias de literatura e suporte teórico e realizada entrevista pontual de apoio nos dias 31/01/2019 e 01/02/2019 com um auditor dentre os primeiros a ingressarem no cargo (no primeiro concurso, de 1997). Por fim, houve validação das propostas elaboradas com os entrevistados, via e-mail institucional, sem retorno de quaisquer discordâncias quanto aos cursos de ação recomendados.

As técnicas de análise consistiram em análise documental, de conteúdo (VERGARA, 2010) e triangulação de dados (TRIVIÑOS, 1987). O uso de fontes múltiplas de evidências apresenta a grande vantagem de desenvolver "linhas convergentes de investigação" (YIN, 2005), muito útil com vistas à elaboração das propostas de intervenção, com a articulação de elementos de diversas fontes, e foi considerado essencial e largamente utilizado nesta pesquisa.

\section{RESULTADOS}

Os resultados apresentaram dados relacionados à competência dos ocupantes do cargo de Auditor Fiscal da Fazenda municipal para, dentre outras, realizar 
fiscalizações e auditorias fiscais e tributárias, consoante lei principal de regência do cargo, Lei Complementar 134/2011 (PARANAGUÁ, 2011). Evidenciaram a existência de 19 ocupantes do cargo, que ingressaram na carreira em três momentos distintos (referentes aos concursos de 1997, 2001 e 2012), além da presença de um estagiário e uma funcionária técnica de recepção de protocolo.

Foi possível perceber a existência de diversos sistemas informatizados ao longo do tempo, utilizados para a consecução das atividades, e de uma pasta em rede, de nome "Fiscais", disponível a todos os auditores. Percebeu-se, ainda, a inexistência de cursos realizados especificamente voltados para a área de operações portuárias, desde 1997, sendo o mais próximo desta área um curso de agenciamento marítimo ministrado por volta de 2003 (do qual não participaram todos os ingressantes do concurso de 2001, haja vista que alguns foram chamados no início do prazo de validade, e outros ao longo dele).

Evidenciaram-se as leis que regem o processo de fiscalização e auditoria de tributos no Município como as seguintes leis federais: LC 116/2003 (BRASIL, 2003) e CTN (Lei 5172, de 1966) (BRASIL, 1966, 1968). Na esfera municipal, a Lei Complementar 06/2000, que instituiu o Código Tributário Municipal (PARANAGUÁ, 2000) e ainda apresenta dispositivos vigentes, a LC 110/2009 (PARANAGUÁ, 2009) e a Lei Complementar 209/2017 referente às alíquotas vigentes atualmente (PARANAGUÁ, 2017). Além das já citadas, ainda vigente se encontra a Lei Complementar 99/2008, que dispõe sobre o processo administrativo tributário municipal (PARANAGUÁ, 2008).

A arrecadação geral de ISS de Paranaguá demonstrou crescimento incessante desde 1997, sendo que dados obtidos pela Prefeitura evidenciaram arrecadação de cerca de 160 milhões de reais no ano de 2018 (PARANAGUÁ, 2018b). O mesmo sistema permitiu verificar que dos 10 maiores arrecadadores, 9 são diretamente relacionados com as operações portuárias, e 1, indiretamente relacionado (IPM SISTEMAS, 2017a).

Quanto aos processos de fiscalização, pode-se perceber que: o processo se inicia com uma Ordem de Serviço da Superintendência, e enquanto alguns entrevistados entendem que devem primeiro notificar o contribuinte, outros entendem que devem primeiro entregar um Termo de Início de Ação Fiscal (TIAF) (quanto a este ponto, percebeu-se que existe previsão legal de que ambos os caminhos são possíveis). Obteve-se informações de que as fiscalizações geralmente são feitas com 2 auditores, um mais e um menos experiente, e de que a duração original do processo é de 60 dias, geralmente insuficiente, necessitando de prorrogações.

Alguns entrevistados entendem que faz parte do processo preliminar a obtenção de informações acerca do contribuinte que será fiscalizado, com uso do sistema de informação da Prefeitura. Alguns entrevistados não souberam conceder respostas por nunca terem realizado fiscalização nesse setor, ou por fazer tanto tempo que a realizaram que não se lembram a ponto de opinar.

Com relação aos recursos e técnicas empregados, constatou-se uso de pesquisa, de conversas com pessoas da área e colegas; requerimento de informações à APPA (autoridade portuária do Porto de Paranaguá) e a terceiros, e a existência de previsão legal para requerer essas informações. O uso de documentos fiscais e livros do contribuinte, de dados de sistema e embasamento em teses já exploradas também apareceu nesta etapa.

Atenção à contas e documentos específicos, existência de fluxogramas orientativos elaborados por diretor, necessidade de conhecimentos gerais contábeis e portuários, e conhecimentos mais aprofundados da atividade em sentido amplo, 
VI CIDESPORT/2019

Congresso Internacional

de Desempenho Portuário

triangulação de informações obtidas por diversas fontes, previsão de situações de presunção de ausência de tributação em lei e falta de instruções normativas ou leis específicas relacionadas à fiscalização de ISS em operações portuárias foram outros dos importantes elementos captados na coleta dos dados.

No que tange às experiências próprias, pode-se perceber que a maioria já realizou fiscalização de ISS em serviços de operações portuárias. Dentre os que já realizaram essas fiscalizações, estes mencionaram: a existência de experiências de fiscalização anteriores; o uso de documentos de diversas fontes, como do contribuinte, dos tomadores, da APPA e da Prefeitura; o uso da fiscalização de contas; a necessidade de conferência, mesmo em caso de pagamento, pela possibilidade de não representarem os valores corretos.

Enquanto alguns dos que realizaram essas fiscalizações apresentaram maior domínio sobre assuntos relacionados, com detalhamentos, explicações e teses, outros não apresentaram riqueza tão grande de conhecimentos e domínio do assunto. Houve também quem mencionasse documentos específicos e modelos em sua posse relacionados à atividade. Houve quem mencionasse experiência profissional anterior no setor. Os que não realizaram essa fiscalização específica ou que não se recordam do assunto mencionaram que não sabiam como fariam, que teriam que pesquisar sobre, e que usariam os colegas como suporte.

Com relação às experiências de terceiros, alguns reconhecem colegas como referência no assunto. Há quem ache que há colegas que usam somente as informações providenciadas pelos sistemas da Prefeitura, e alguns mencionaram desconhecer outras maneiras de realizar a fiscalização dessas atividades. Há relato de não ter acesso a como os outros colegas trabalham, bem como de trocas informais de experiências e conversas entre os colegas de trabalho.

Ao serem abordados sobre as dificuldades encontradas, muitos entrevistados se manifestaram no sentido de que entendem a área como complexa, no que diz respeito ao conteúdo, à documentação, à constante mutação e atualização necessária e à abrangência do tema, multidisciplinar, de vários atores e serviços envolvidos. Foram mencionadas dificuldades em termos utilizados na área portuária, por sua especificidade, e na compreensão dos valores. Foram também mencionadas dificuldades de compreensão dos livros e documentos fiscais relacionados à área.

Foi mencionada a elaboração de várias tarefas concomitantemente, e que muitos ficam tempos sem ter contato com a área; bem como a informação de que vários processos vão para o litigioso. Também foi mencionada a falta de direcionamento, de desconhecimento de um ponto específico da área para concentrar esforços de fiscalização; e que o sistema não atende completamente às necessidades a ponto de ser estrategicamente relevante. $O$ fato de as atividades portuárias envolverem relações internacionais também se apresentou como ponto que dificulta a fiscalização, o acesso e a compreensão da documentação. Da mesma forma, foi identificado pelos entrevistados que o padrão de 60 dias é inviável para o porte deste tipo de fiscalização; a dificuldade de entender a logística portuária como um todo e os documentos contábeis a ela relacionados; e a inexistência de treinamentos e cursos proporcionados pela Prefeitura focados na área.

As sugestões de melhorias de processo foram assim manifestadas pelos entrevistados: aprimorar conhecimentos e atualizá-los constantemente; , ir a cidades próximas/ aproximar contatos com outros municípios; ter um bom relacionamento entre Prefeitura e Porto; trabalhar com equipes, lideradas por pessoas experientes; desenvolver métodos e padrões de trabalho; ter um sistema informatizado próprio, melhorar o atual e ter mais apoio técnico no sistema atual; contar com apoio e vontade 
política; ter mais pessoal trabalhando, com novo concurso para auditores fiscais; ter mais ferramentas à disposição: cursos, treinamentos e especializações; focar a atenção em processos de fiscalização que dão maior retorno financeiro; atacar nichos específicos, provocando resposta da maioria da área; mostrar presença fiscal e aumentar a frequência de auditoria nesses serviços específicos; realizar mais visitas in loco, aumentar a constância de acompanhamento e experiência prática; utilizar novas obrigações acessórias; operacionalizar a possibilidade de que a APPA envie informações à Prefeitura, e que esta esteja apta a recebê-las, introduzi-las ao sistema, armazená-las e disponibilizá-las em relatórios analíticos e de cruzamentos de dados; modificar a nota fiscal atual desses prestadores específicos requerendo maior detalhamento. As sugestões de minimização de gargalos, por sua vez, concentraramse na necessidade de realizar cursos, capacitações e treinamentos foi menção unânime nos relatos, e no uso da prática como forma de angariar conhecimentos.

A análise das informações coletadas nas entrevistas e nos documentos acessados, amparadas nas teorias apresentadas no referencial teórico do estudo permitiu a compreensão de campos a serem trabalhados e aprimorados, de características da atividade fiscalizatória e seu processo, experiências, gaps e dificuldades, dentro do contexto objeto da pesquisa, e permitiu a elaboração de propostas de intervenção e recomendações para o aprimoramento do processo.

O aprimoramento pretendido dos processos pode, assim, ser trabalhado em vertentes complementares, separadas por tópicos a fim de melhor visualização, compreendendo atuação interna, investimentos e atuação externa. Na medida do possível, foram elaboradas as sugestões de maneira a evidenciarem, ao máximo, caminhos para torná-las possíveis e auferir delas benefícios. A ideia de se propor um conjunto de ações tem relação com a visão sistêmica da situação, enxergando a oportunidade por vários prismas.

$\mathrm{Na}$ vertente de atuação interna, as recomendações incluíram o compartilhamento de conhecimentos através da divulgação da pesquisa, a sugestão de reuniões periódicas intra e interdepartamentais, o uso da pasta de rede "Fiscais" para compartilhar teses e materiais, a criação de eventos para troca de conhecimentos e fortalecimento da imagem institucional, e o apadrinhamento de novos entrantes pelos servidores já atuantes, a fim de repassar conhecimento e auxiliar no início da carreira.

Ainda em atuação interna, pode-se perceber a necessidade de padronização de procedimentos de início de fiscalização, sugerindo-se que esse se faça com a entrega da TIAF inicialmente (não deixando espaço de dúvidas para o descabimento de denúncia espontânea após esse ato), aproximação com a Procuradoria Jurídica, rodízio de temas e de processos de fiscalização (para que todos estejam em constante atualização), equipes lideradas por auditores experientes, aumento de frequência de auditoria no setor portuário (dada a sua importância) e conscientização de chefia e autoridades.

Em investimentos, no que diz respeito a recursos humanos, sugeriu-se a realização de novo concurso, haja vista existência de vagas tantas quantas as existentes quando da realização do último certame em 2012; além disso, a contratação de técnicos de apoio para atividades administrativas e de menor complexidade, ou realocação de servidores da prefeitura para esse fim. Investimentos em tecnologias da informação e sistemas foram sugeridos via análise de viabilidade de criação de um sistema interno próprio e, em outra via, aprimoramento do sistema atual e do atendimento técnico, com aumento da quantidade de profissionais disponíveis para atendimento. 
VI CIDESPORT/2019

Congresso Internacional

de Desempenho Portuário

Alterações legislativas e investimentos em tecnologia da informação também foram previstas, com ênfase à criação de obrigação acessória da APPA encaminhar informações referentes às atividades portuárias à Prefeitura, abastecendo um banco de dados capaz de, via sistema, gerar relatórios estratégicos. Alteração da nota fiscal eletrônica para serviços portuários, obrigando o preenchimento de outros campos desnecessários a outros serviços, como dados do navio, da carga, tonelagem, agenciador etc., também foi uma sugestão elaborada com base nos relatos analisados. Ainda em investimentos, notável a importância de treinamentos, cursos e capacitações voltadas ao aprendizado e manutenção e atualização de conhecimentos dos funcionários em setor tão complexo e dinâmico.

A respeito da vertente de atuação externa, sugeriram-se visitas in loco ao Porto com maior frequência, aproximações da Prefeitura com o Porto, contato com a Prefeitura de outros municípios portuários, reativação da Associação Brasileira de Municípios portuários (associação que aproximava municípios portuários e hoje se encontra inativa e irregular, e cuja última gestão foi de responsabilidade de falecido Prefeito de Paranaguá, conforme informações colhidas na Receita Federal do Brasil em 2018 e 2019 após menção em relato de entrevistado). O repasse de conhecimentos à sociedade também fez parte das iniciativas de atuação externa capazes de influenciar na educação fiscal e no cumprimento tributário e auxiliarem o processo como um todo.

Percebem-se, assim, variadas ações nas três vertentes sugeridas, adaptadas à realidade da fiscalização de ISS em operações portuárias no município de Paranaguá - PR. Enxergam-se nas ações propostas tanto características particulares de execução e de recursos necessários quanto inter-relações, o que coaduna com a visão holística do processo e a oportunidade vislumbrada de aperfeiçoamento. Acredita-se no potencial das recomendações sugeridas para nortear a atuação estatal no aperfeiçoamento dos processos fiscalizatórios, atendendo positivamente aos objetivos do estudo proposto.

\section{CONCLUSÕES}

A pesquisa apresentada propôs alternativas para o aperfeiçoamento do processo de fiscalização tributária de ISS no setor portuário do município de Paranaguá - PR. A ótica abordada foi a de percepção de oportunidade de aprimoramento de atividade que envolve a prestação de serviços públicos pelos auditores fiscais do município, vislumbrando a aproximação da sempre perseguida eficiência administrativa, pautada em processos de melhoria constante, visando sempre, ao final, ampliar as possibilidades de concretização de satisfação dos interesses sociais e de vivência digna à população.

A descrição dos processos fiscalizatórios e de experiências permitiu evidenciar níveis distintos de conhecimento entre os entrevistados, resultados alcançados, técnicas de fiscalização e experiências, teses, existência de referências e conhecimentos internos, necessidades de capacitação e atualização constantes e compartilhamento entre os entrevistados da importância em desempenhar da melhor forma possível a fiscalização em área tão essencial ao Município. As dificuldades relacionaram-se, em sua maioria, com investimentos, informatização, ambiente dinâmico e assunto complexo.

Sugestões foram elaboradas pelos próprios entrevistados, e foram altamente consideradas na formulação das ações propostas de intervenção. Em paralelo aos resultados satisfatórios do corpo técnico, campo de aperfeiçoamento foi reconhecido, 
VI CIDESPORT/2019

Congresso Internacional

de Desempenho Portuário

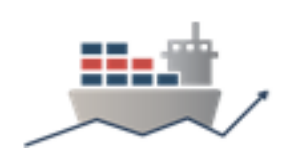

inclusive considerando uma previsão de duplicação do volume movimentado pelo Porto até 2030, gerando propostas nas vertentes de atuação interna, externa e de investimentos, com viabilidade de implementação. Essas propostas consideraram a situação do ambiente alvo do estudo e visaram o aperfeiçoamento dos processos e esforços relacionados às atividades em questão, com base em diversas fontes. Observou-se que o aperfeiçoamento desejado tanto é possível quanto viável, e que, caso ocorra, apresenta potencial transformador e coaduna com a perseguição de excelência no desempenho dos serviços públicos, sempre pautado na busca pela satisfação dos anseios coletivos.

As contribuições se dão à Academia, preenchendo lacuna de escassa produção; ao ente público e aos auditores fiscais, aproximando-os de sua finalidade e valorizando sua atuação; e à sociedade, ampliando as chances de receber um serviço público de melhor qualidade e eficiência. A intenção manifesta é a de que impactos práticos sejam sentidos com a pesquisa desenvolvida, servindo de guia norteador $\mathrm{e}$ modelo de ação aos gestores públicos, atentando-os para o caso aqui levantado e para a constante atualização dos processos, gerando reflexões e atuações que busquem a melhoria dos serviços ofertados.

Recomendam-se, por fim, como trabalhos futuros, o desenho de um sistema integrado do processo de fiscalização estudado que contemple visão sistêmica; o acompanhamento da realidade de outros municípios brasileiros com Portos; estudos relacionando o ISS municipal e o crescimento do porto; e estudos verificando a tendência do crescimento de arrecadação de ISS em Paranaguá. Com a realização dos estudos propostos, infere-se que seria possível pensar o aprimoramento da fiscalização do ISS em operações portuárias em um contexto ainda mais amplo, permitindo, cada vez mais, que a atuação estatal alcance os resultados almejados pela população em seu papel de promotor dos direitos sociais e facilitador da existência digna de todos os seres.

\section{REFERÊNCIAS}

AEN (AGÊNCIA ESTADUAL DE NOTÍCIAS DO PARANÁ). Porto contribui para crescimento econômico e social de Paranaguá. Curitiba, 2017. Disponível em $<$ http://www.aen.pr.gov.br/modules/noticias/article. .php?storyid=92248\&tit=Portocontribuipara-crescimento-economico-e-social-de-Paranagua>. Acesso em: 31 maio 2018.

AFONSO, José Roberto Rodrigues et al. Municípios, arrecadação e administração tributária: quebrando tabus. Brasília, 1998. Disponível em: $<$ https://www.bndes.gov.br/SiteBNDES/export/sites/default/bndes_pt/Galerias/Arquiv os/conhecimento/revista/rev1001.pdf >. Acesso em: 07 mai. 2018.

ALEXANDRE, Ricardo. Direito tributário esquematizado. Rio de Janeiro: Forense; São Paulo: Método, 2015.

ALLINGHAM, Michael G.; SANDMO, Agnar. Income tax evasion: a theoretical analysis. Journal of Public Economics, Noruega, v. 1, p. 323338, 1972.

ALVES, Magda. Como escrever teses e monografias. Rio de Janeiro: Elsevier, 2003.

AMARO, Luciano. Direito tributário brasileiro. São Paulo: Saraiva, 2013. 
VI CIDESPORT/2019

Congresso Internacional

de Desempenho Portuário

ANTAQ (AGÊNCIA NACIONAL DE TRANSPORTES AQUAVIÁRIOS). Estatístico aquaviário. Brasília, 2018. Disponível em: <http://web.antaq.gov.br/Anuario/>. Acesso em: 5 jun. 2018.

APPA (ADMINISTRAÇÃO DOS PORTOS DE PARANAGUÁ E ANTONINA). Administração dos portos de Paranaguá e Antonina. Paranaguá, 2018a. Disponível em: <http://www. portosdoparana.pr.gov.br/>. Acesso em: 18 mai. 2018. APPA (ADMINISTRAÇÃO DOS PORTOS DE PARANAGUÁ E ANTONINA). Caderno de Resultados. Relatório de Gestão da Administração dos Portos de Paranaguá e Antonina (APPA) 2011-2017. Paranaguá, 2018b. Disponível em: <Ahttp://www.portosdoparana.pr.gov.br/arquivos/File/Caderno_resultados_APPA_20 18_1.p df > . Acesso em: 01 mar. 2019.

APPA (ADMINISTRAÇÃO DOS PORTOS DE PARANAGUÁ E ANTONINA). Dicionário básico portuário. 3. ed. Paranaguá, 2016. Disponível em: $<$ http://www. portosdoparana.pr.gov.br/arquivos/File/APDICIONARIO.pdf >. Acesso em: 02 mai. 2018.

ARAÚJO NETO, Pedro Lopes; SILVA, José Dionísio Gomes da. Considerações sobre a contribuição da contabilidade para a administração tributária. Revista Ambiente Contábil, Natal, v. 1. n. 1, p. 22-36, 2009.

BERTOLUCCI, Aldo V.; NASCIMENTO, Diogo Toledo do. Quanto custa pagar tributos? Revista Contabilidade \& Finanças, São Paulo, n. 29, p. 55 - 67, 2002. BRASIL. Constituição da República Federativa do Brasil de 1988. Brasília, 1988. Disponível em: <http://www.planalto.gov.br/ccivil_03/constituicao/constituicao.htm>. Acesso em: 28 abr. 2018.

BRASIL. Lei 5.172, de 25 de outubro de 1966. Dispõe sobre o Sistema Tributário Nacional e institui normas gerais de direito tributário aplicáveis à União, Estados e Municípios. Brasília, 1966. Disponível em:

<http://www.planalto.gov.br/ccivil_03/leis/L5172Compilado.htm>. Acesso em: 28 abr. 2018.

BRASIL. Lei 10.406, de 10 de janeiro de 2002. Institui o Código Civil. Brasília, 2002. Disponível em: <http://www.planalto.gov.br/ccivil_03/leis/2002//10406.htm> . Acesso em: 28 abr. 2018.

BRASIL. Lei 12.815, de 5 de junho de 2013. Dispõe sobre a exploração direta e indireta pela União de portos e instalações portuárias e sobre as atividades desempenhadas pelos operadores portuários; altera as Leis nos 5.025, de 10 de junho de 1966, 10.233, de 5 de junho de 2001, 10.683, de 28 de maio de 2003, 9.719, de 27 de novembro de 1998, e 8.213, de 24 de julho de 1991; revoga as Leis nos 8.630, de 25 de fevereiro de 1993, e 11.610, de 12 de dezembro de 2007, e dispositivos das Leis nos 11.314, de 3 de julho de 2006, e 11.518, de 5 de setembro de 2007; e dá outras providências. Brasília, 2013. Disponível em:

$<$ http://www.planalto.gov.br/ccivil_03/_ato2011-2014/2013/lei/l12815.htm>. Acesso em: 23 abr. 2018. 
VI CIDESPORT/2019

Congresso Internacional

de Desempenho Portuário

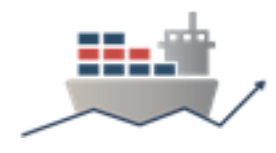

BRASIL. Lei Complementar 116, de 31 de julho de 2003. Dispõe sobre o Imposto Sobre Serviços de Qualquer Natureza, de competência dos Municípios e do Distrito Federal, e dá outras providências. Brasília, 2003. Disponível em:

<http://www.planalto.gov.br/ccivil_03/leis/lcp/lcp116.htm>. Acesso em: 28 abr. 2018.

CAMPANHA, Alexssandro. A auditoria tributária como instrumento otimizador da receita própria municipal: a experiência do município de Vitória da Conquista.

Cadernos de Ciências Sociais Aplicadas, Vitória da Conquista, n. 9. p. 81-108, 2010.

CARVALHO, Daniela Moreira de; PRÉVOT, Fréderic; MACHADO, João Armando Dessimon. O uso da teoria da visão baseada em recursos em propriedades rurais: uma revisão sistemática da literatura. Revista de Administração da Universidade de São Paulo, São Paulo, v.49, n.3, p.506-518, 2014.

CFC (CONSELHO FEDERAL DE CONTABILIDADE). Norma brasileira de contabilidade - NBC TA 200 (R1), de 19 de agosto de 2016. Altera a NBC TA 200 que dispõe sobre os objetivos gerais do auditor independente e a condução da auditoria em conformidade com normas de auditoria. Resoluções e ementas do

CFC. Brasília, 2016. Disponível em:

<http://www2.cfc.org.br/sisweb/sre/detalhes_sre.aspx?Codigo=2016/NBCTA200(R1) $>$. Acesso em: 19 jun. 2018.

CHANG, Otto H.; NICHOLS, Donald R.; SCHULTZ, Joseph J. Taxpayers attitudes toward tax audit risk. Journal of Economic Psychology, Noruega, v. 8, n.3, p. 299309, set. 1987.

COMPARA BRASIL. Municípios. Consultar um Município. Paraná. Paranaguá. Tributos. Preços Correntes. 01/2010 a 12/2017. Disponível em:

$<$ http://comparabrasil.com/municipios/paginas/modulo1.aspx>. Acesso em: 04 dez. 2018.

CURY, Samia Vera. Fiscalização tributária: um estudo de caso no setor de fiscalização do ISSQN do município de Novo Hamburgo - RS. 2013. 59p. Monografia (Curso de Especialização do Programa de Pós-Graduação em Gestão Pública) - Universidade Federal de Santa Maria, Novo Hamburgo, 2013.

FELIPE JÚNIOR, Nelson Fernandes. O setor portuário e marítimo brasileiro: avanços e limitações. Geofronter, Campo Grande, n. 1, v. 1, p. 67-87, 2015.

FERREIRA, Maria das Graças; KANAANE, Solange; SEVERINO, Fátima Regina Giannasi. Aspectos comportamentais na gestão de pessoas. In: KANAANE, Roberto;

FIEL FILHO, Alécio; FERREIRA, Maria das Graças (Orgs.). Gestão pública: planejamento, processos, sistemas de informação e pessoas. São Paulo: Atlas, 2010. 
VI CIDESPORT/2019

Congresso Internacional

de Desempenho Portuário

FOLLONI; André; DIB, Natalia Brasil. Notas sobre a tributação como bem jurídico coletivo. Revista de Estudos Constitucionais, Hermenêutica e Teoria do Direito (RECHTD), São Leopoldo, v.7, n.3, p.323-333, 2015.

FRANÇA, Reginaldo de. Fiscalização tributária: prerrogativas e limites. Editora Juruá: Curitiba, 2012.

GIL, Maria das Graças da Costa. Análise do programa de modernização da administração tributária no âmbito da SEMEF de MANAUS/AM. 2002. 139p. Dissertação (Mestrado) - Universidade Federal de Santa Catarina, Florianópolis 2002.

GODOY, Amalia Maria Goldberg. Reestruturação Produtiva e Polarização do Mercado de Trabalho em Paranaguá - PR. Revista Paranaense de Desenvolvimento, Curitiba, n. 99, p. 5-25, 2000.

GODOY, Luciano de Souza; BASSO, Juliana Penha. Sonegação e inadimplência contumaz: prejuízo à concorrência empresarial. Revista Digital ESAPERGS, Rio Grande do Sul, 2015.

GRZYBOVSKI, Denize; KAHN, Tatiana Gaertner. Educação fiscal: premissa para melhor percepção da questão tributária. Revista de Administração Pública, Rio de Janeiro, v. 40, n. 5, p. 841-864, 2006.

IBGE (INSTITUTO BRASILEIRO DE GEOGRAFIA E ESTATÍSTICA). Cidades. 2018. Disponível em: <https://cidades.ibge.gov.br/brasil/pr/paranagua/panorama>. Acesso em: 5 jun. 2018.

IPM SISTEMAS. Prefeitura Municipal de Paranaguá: Gerenciamento de Indicadores. Indicador Padrão de Gestão. Tributos Mais Arrecadados. Paranaguá, 2017a.

IPM SISTEMAS. Prefeitura Municipal de Paranaguá: Relatório de Maiores Receitas por Itens da Lista de Serviço. Prestado, Tomado, Eventual Prestado, Eventual Tomado. Competência: de 01/2015 até 12/2017. Paranaguá, 2017b.

KORFF, Eurico. Finanças públicas municipais. In: Revista de Administração de empresas, Rio de janeiro, ano 1, v.17, n. 5, p. 7-41, 1977.

LAGIOIA, Umbelina Cravo Teixeira et al. Aplicabilidade da Lei de Newcomb-Benford nas fiscalizações do imposto sobre serviços - ISS. Revista Contabilidade

Financeira, São Paulo, v. 22, n. 56, p. 203-224, 2011.

LEITE, Luana Priscilla Carreiro Varão. O Sistema tributário brasileiro: análise da sonegação fiscal nas empresas brasileiras. 2011. 89p. Trabalho de Conclusão de Curso (Graduação) - Universidade Federal de Santa Catarina, Florianópolis, 2011.

MACHADO, Edson Moraes de. A questão portuária nacional: o caso do Estado do Espírito Santo. 2016. 196p. Dissertação (Mestrado) - Universidade Federal de Santa Catarina, Florianópolis, 2016. 
VI CIDESPORT/2019

Congresso Internacional

de Desempenho Portuário

MACHADO, Hugo de Brito. Crimes contra a ordem tributária. São Paulo: Atlas, 2009.

MADEIRA, José Maria Pinheiro. Administração pública, tomo 1. Rio de Janeiro: Elsevier, 2010.

MARIA, Elizabeth de Jesus; LUCHIEZI JÚNIOR, Álvaro. Tributação no Brasil: em busca da justiça fiscal. Brasília, 2010.

MARTINS, Patrick Figueiredo. Funcionamento do processo de fiscalização do ISS do município de Palhoça. 2016. 43p. Trabalho de Conclusão de Curso (Monografia de Graduação) - Universidade Federal de Santa Catarina, Florianópolis, 2016.

MARTINS, Sergio Pinto. Manual de direito tributário. São Paulo: Atlas, 2009.

MATTOZO, João Geraldo Orzenn. A gestão do armazenamento de granéis sólidos no Porto de Paranaguá. 2006. 99p. Monografia (MBA Portos e Logística Empresarial) - Universidade Católica de Santos, Paranaguá, 2006.

MINISTÉRIO DA FAZENDA. Receita Federal do Brasil. Centro de Estudos Tributários e Aduaneiros (CETAD). Carga Tributária no Brasil 2017. Análise por Tributos e Bases de Incidência. Brasília, Novembro de 2018. Disponível em: $<$ http://receita.economia.gov.br/dados/receitadata/estudos-e-tributarios-eaduaneiros/estudose-estatisticas/carga-tributaria-no-brasil/carga-tributaria2017.pdf>. Acesso em: 27 dez. 2018.

MIRANDA, Antonio Jose Areias. 0 combate à fraude e evasão fiscais: a atuação da administração tributária e a avaliação dos resultados obtidos. 2013. 76p. Dissertação (Mestrado em Auditoria) - Instituto Superior de Contabilidade e Administração do Porto, Porto, 2013.

MONIÉ, Frédéric; VIDAL, Soraia Maria do S. C. Cidades, portos e cidades portuárias na era da integração produtiva. Revista de Administração Pública, v.40, n.6, 975995., 2006.

NABAIS, José Casalta. Nota sobre o dever fundamental de pagar tributos. In: ALLEMAND, Luiz Cláudio Silva (Coord.). Direito tributário: questões atuais. Brasília: OAB, Conselho Federal, Comissão Especial de Direito Tributário, 2012.

OLIVEIRA, Margarida Isabel Melo de. A auditoria tributária e a detecção de comportamento evasivo. 2012. 85p. Dissertação (Mestre em Contabilidade Ramo Fiscalidade) - Instituto Superior de Contabilidade e Administração da Universidade de Aveiro, 2012.

PAIVA, Valfredo. Tributação, arrecadação e política fiscal - um estudo de caso: o Programa de modernização da administração tributária do município de Vitória. 2005. 144p. Dissertação (Mestrado Profissional) - Fundação Instituto Capixaba de Pesquisas em Contabilidade, Economia e Finanças (FUCAPE), Vitória, 2005. 
VI CIDESPORT/2019

Congresso Internacional

de Desempenho Portuário

PANTOJA; Gabriela S.; PENALOZA, Rodrigo S. Tax evasion under behavioral structures. EconomiA, Niterói, v.15, edição 1, p. 30-40, 2014.

PARANAGUÁ. A Cidade. História. Paranaguá, 2018a. Disponível em: <http://www.paranagua.pr.gov.br/conteudo/a-cidade/historia>. Acesso em: 31 out. 2018.

PARANAGUÁ. Lei Complementar 06, de 21 de dezembro de 2000. Dispõe sobre o sistema tributário do Município de Paranaguá - PR, e dá outras providências. Leis municipais. Paranaguá, 2000. Disponível em: < https://leismunicipais.com.br/a/pr/p/paranagua/leicomplementar/2000/1/6/leicomplementar-n-6-2000-dispoe-sobre-o-sistema-tributario-domunicipio-deparanagua-pr-e-da-outras-providencias?q=06>. Acesso em: 08 out. 2018.

PARANAGUÁ. Lei Complementar 99, de 18 de dezembro de 2008. Estabelece o procedimento e o processo administrativo tributário e dá outras providências. Leis municipais. Paranaguá, 2008. Disponível em:

$<$ https://leismunicipais.com.br/a/pr/p/paranagua/lei-

complementar/2008/10/99/leicomplementar-n-99-2008-estabelece-o-procedimentoe-o-processo-administrativo-tributarioe-da-outras-providencias?q=99>. Acesso em: 04 fev. 2019.

PARANAGUÁ. Lei Complementar 110, de 18 de dezembro de 2009. Dispõe sobre as normas relativas ao imposto sobre serviços de qualquer natureza ISSQN e taxas municipais, acrescentando e alterando dispositivos na Lei Complementar n. 06, de 21 de dezembro de 2000, Código Tributário Municipal, e dá outras providências. Leis municipais. Paranaguá, 20092. Disponível em:

$<$ https://leismunicipais.com.br/a/pr/p/paranagua/leicomplementar/2009/11/110/leicomplementar-n-110-2009-dispoe-sobre-as-normas-relativasao-imposto-sobreservicos-de-qualquer-natureza-issqn-e-taxas-municipais-acrescentando-ealterandodispositivos-na-lei-complementar-n-06-de-21-de-dezembro-de-2000-codigotributariomunicipal-e-da-outras-providencias?q=110>. Acesso em: 08 mai. 2018.

PARANAGUÁ. Lei Complementar n. 134, de 23 de dezembro de 2011. Cria, na estrutura administrativa do Poder Executivo do Município de Paranaguá, o cargo efetivo de auditor fiscal da fazenda municipal, altera a nomenclatura do cargo de fiscal da receita tributária e dispositivos da Lei Complementar n. 0482006, e dá outras providências. Leis municipais. Paranaguá, 2011. Disponível em: < https://leismunicipais.com.br/a/pr/p/paranagua/leicomplementar/2011/14/134/leicomplementar-n-134-2011-cria-na-estrutura-administrativado-poder-executivo-domunicipio-de-paranagua-o-cargo-efetivo-de-auditor-fiscal-da-fazendamunicipalaltera-a-nomenclatura-do-cargo-de-fiscal-da-receita-tributaria-e-dispositivos-daleicomplementar-n-048-2006-e-da-outras-providencias?q=134>. Acesso em: 04 fev. 2019.

PARANAGUÁ. Lei Complementar 209, de 22 de dezembro de 2017. Altera a Lei Complementar $n^{\circ}$ 147, de 20 de dezembro de 2012, que Institui a Taxa de Embarque de Passageiros, e altera os Anexos da Lei Complementar $n^{0} 111 / 2009$. Leis municipais. Paranaguá, 2017b. Disponível em: < https://leismunicipais.com.br/a/pr/p/paranagua/leicomplementar/2017/21/209/lei- 
VI CIDESPORT/2019

Congresso Internacional

de Desempenho Portuário

complementar-n-209-2017-altera-a-lei-complementar-n-147de-20-de-dezembro-de2012-que-institui-a-taxa-de-embarque-de-passageiros-e-altera-osanexos-da-leicomplementar-n-111-2009?q=209>. Acesso em: 08 out. 2018.

PARANAGUÁ. Secretário da Fazenda presta contas e destaca aumento de 10\% na arrecadação municipal de Paranaguá. Notícia. 31 mai. 2017. Paranaguá, 2017c.

Disponível em: <http://www.paranagua.pr.gov.br/noticias/noticia9780.html>. Acesso em: 05 jun. 2018.

PARANAGUÁ. Portal da transparência. Tributos arrecadados. Data de igual 01/01/2014 até Igual 31/12/2017. Descrição da conta contem Imposto Sobre Serviço. Paranaguá, 2018b. Disponível em:

$<$ https://paranagua.atende.net/?pg=transparencia\#!/grupo/2/item/3/tipo/1>. Acesso em: 05 jun. 2018.

PEREIRA, Ivone Vieira. Fatores que influenciam o comportamento desonesto das pessoas na prática da evasão fiscal no Brasil. 2017. 147 f., il. Tese (Doutorado em Ciências Contábeis)—Programa Multi-Institucional e Inter-Regional de Pós-Graduação em Ciências Contábeis, Universidade de Brasília, Universidade Federal da Paraíba, Universidade Federal do Rio Grande do Norte, Brasília, 2017.

PUGLIESI, Fábio. Contribuinte e administração tributária na globalização. Curitiba: Juruá, 2010.

RAUEN, Fábio José. Roteiros de iniciação científica: os primeiros passos da pesquisa científica desde a concepção até a produção e a apresentação. Palhoça: Ed. Unisul, 2015.

RAUPP, Fabiano Maury; BEUREN, Ilse Maria. Metodologia da pesquisa aplicável às ciências sociais. In: BEUREN, Ilse Maria (Org.). Como elaborar trabalhos monográficos em contabilidade: teoria e prática. São Paulo: Atlas, 2003.

RECEITA FEDERAL DO BRASIL. Emissão de comprovante de inscrição e de situação cadastral. 2019. Disponível em:

<http://www.receita.fazenda.gov.br/PessoaJuridica/CNPJ/cnpjreva/Cnpjreva_Solicita cao.asp>. Acesso em: 22 fev. 2019.

RIBEIRO, Marcelo Gollo. Aspectos da gestão tributária no Município. Revista Jus Navigandi, Teresina, ano 16, n. 2850, 2011.

SANTOS, Clezio Saldanha dos. Introdução à gestão pública. São Paulo: Saraiva, 2006.

SCHMITZ, Andiara Faber Pereira. As percepções dos fiscais da Secretaria de Estado da Fazenda de Santa Catarina acerca dos benefícios da utilização da nota fiscal eletrônica pelos contribuintes catarinenses. 2010. 59p. Trabalho de Conclusão de Curso (Graduação) - Universidade Federal de Santa Catarina, Florianópolis, 2010.

SECCHI, Leonardo. Análise de políticas públicas: diagnóstico de problemas, recomendação de soluções. São Paulo: Cengage learning, 2016. 
VI CIDESPORT/2019

Congresso Internacional

de Desempenho Portuário

SECCHI, Leonardo. Políticas públicas: conceitos, esquemas de análise, casos práticos. São Paulo: Cengage learning, 2013.

SEIXAS, André de. Municípios portuários podem ter direito ao ISS sobre o THC. UPRJ: site dos usuários dos Portos do Rio de Janeiro. 2014. Disponível em: $<$ HTTP://www.uprj.com;br/municipios-podem-ter-direito-ao-iss-sobre-o-thc.html>. Acesso em: 07 maio 2018

SINDOGEESP (SINDICATO DOS OPERADORES EM APARELHOS GUINDASTESCOS, EMPILHADEIRAS, MÁQUINAS E EQUIPAMENTOS TRANSPORTADORES DE CARGA DOS PORTOS E TERMINAIS MARÍTIMOS E FLUVIAIS DO ESTADO DE SÃO PAULO). Sistema inteligente faz mapeamento no Porto de Santos para inibir evasão fiscal. Notícias. 08 jul. 2013. Disponível em: <http://www.sindogeesp.com.br/noticia/sistemainteligente-faz-mapeamento-noporto-de-santos-para-inibir-evasao-fiscal>. Acesso em: 07 fev. 2019.

SIQUEIRA, Marcelo Lettieri; RAMOS, Francisco S. A economia da sonegação: teorias e evidências empíricas. Revista de Economia contemporânea, Rio de Janeiro, ano 4, v. 9, n.3, p. 555-581, 2005.

SOARES, Carlos Roberto. Os portos de Paranaguá (PR) e Itajaí (SC): análise comparativa das suas relações com as cidades de inserção, da estrutura operacional atual e das condições sócio-ambientais das regiões de entorno. 2009. 184p. Tese (Doutorado) - Universidade Federal do Paraná, Curitiba, 2009.

SOARES NETO, Antonio; SILVA, Anielson Barbosa da. Os estágios de aprendizagem de auditores fiscais no contexto da prática profissional. Revista de Administração Pública, Rio de Janeiro, ano 11, v.46, n.3, p. 841-863, 2012.

STF (SUPREMO TRIBUNAL FEDERAL). Súmula 439. Data de Aprovação: Sessão Plenária de 01/10/1964. Fonte de Publicação: DJ de 08/10/1964, p. 3645; DJ de 09/10/1964, p. 3665; DJ de 12/10/1964, p. 3697. Disponível em:

<http://www.stf.jus.br/portal/jurisprudencia/listarJurisprudencia.asp?s1=439.NUME.\% 20NA O\%20S.FLSV.\&base=baseSumulas>. Acesso em: 28 abr. 2018.

TCU (TRIBUNAL DE CONTAS DA UNIÃO). Secretaria Geral de Controle Externo. Secretaria Adjunta de Normas e Procedimentos. Diretoria de Métodos e Procedimentos de Controle. Análise de documentos fiscais relacionados a fraude na administração pública. Brasília- DF, set./2003. Disponível em: $<$ http://portal.tcu.gov.br/controle-externo/normas-eorientacoes/tecnicas-estudos-eferramentas-de-apoio/>. Acesso em: 1 jun. 2018.

TRIVIÑOS, Augusto Nibaldo Silva. Introdução à pesquisa em ciências sociais: a pesquisa qualitativa em educação. São Paulo: Atlas, 1987.

TUROLLA, Frederico Araujo. Responsabilidade fiscal e investimento público no Brasil. In: VASCONCELLOS, Roberto França de. Direito tributário: política fiscal. São Paulo: Saraiva, 2009.

VERGARA, Sylvia Constant. Métodos de pesquisa em administração. São Paulo: Atlas, 2010. 
VI CIDESPORT/2019

Congresso Internacional

de Desempenho Portuário

VIOL, Andrea Lemgruber. A administração tributária moderna e a maximização do cumprimento tributário: algumas reflexões sobre o caso brasileiro. Revista da

Receita Federal: estudos tributários e aduaneiros, Brasília, v.1., n.2, p. 50-82, 2015.

YIN, Robert K. Estudo de caso: planejamento e métodos. 3. ed. Porto Alegre: Bookman, 2005.

YOSHIURA, Elizabete Issuzu Kinosita. Governança tributária: um estudo da administração tributária do município de Bauru - SP. 2016. 96p. Dissertação (Mestrado) - Centro Universitário de Araraquara, Araraquara, 2016.

ZILVETI, Fernando Aurelio; COELHO, Monica Pereira. O imposto sobre serviços e competência federativa. In: SANTI, Eurico Marcos Diniz de; ZILVETI, Fernando Aurelio (Coords.). Direito tributário: tributação empresarial. São Paulo: Saraiva, 2009. 